\title{
Mechanical Ventilation-Related Safety Incidents in General Care Wards and ICU Settings
}

\author{
Tadashi Kamio MD and Ken Masamune PhD
}

\begin{abstract}
BACKGROUND: Although the ICU is the most appropriate place to care for mechanically ventilated patients, a considerable number are ventilated in general medical care wards all over the world. However, adverse events focusing on mechanically ventilated patients in general care have not been explored. METHODS: Data from the Japan Council for Quality Health Care database were analyzed. Patient safety incidents from January 2010 to November 2017 regarding mechanical ventilation were collected, and comparisons of patient safety incidents between ICUs/high care units (HCUs) and general care wards were made. RESULTS: We identified 261 adverse events (with at least 20 adverse events resulting in death) and 702 near-miss events related to mechanical ventilation in Japan between 2010 and 2017. Furthermore, among all adverse events, 19\% (49 of 261 events) caused serious harm (residual disability or death). Human-factor issues were most frequent in both ICU/HCU and general care settings (55\% and 53\%, respectively), while knowledge-based errors were higher in the general care setting. CONCLUSIONS: Human-factor issues were the most frequent reasons in both settings, while knowledge-based error rates were higher in general care. Our results suggest that proper education and training is needed to minimize patient safety incidents in facilities without respiratory therapists. Key words: incident report; adverse event; general ward; ICU; mechanical ventilation; Japan Council for Quality Health Care; patient safety. [Respir Care 2018;63(10):1246-1252. (C) 2018 Daedalus Enterprises]
\end{abstract}

\section{Introduction}

Incident reporting systems are important in all medical disciplines and health care systems, and such reporting systems are now well established in many countries. ${ }^{1,2}$ These systems can provide important insights into how and why patients can be harmed at the organizational level. Many current health care policies have developed as a

\footnotetext{
Dr Kamio is affiliated with the Department of Anesthesiology and Critical Care Medicine, Jichi Medical University Saitama Medical Center, Saitama, Japan. Drs Kamio and Masamune are affiliated with Joint Graduate School of Tokyo Women's Medical University and Waseda University Cooperative Major in Advanced Biomedical Sciences, Tokyo, Japan.
}

The authors have disclosed no conflicts of interest.

Correspondence: Tadashi Kamio MD, Department of Anesthesiology and Critical Care Medicine, Jichi Medical University Saitama Medical Center, 1-847 Amanumacho, Omiya-ku, Saitama, Japan. E-mail: tadashi-kamio@mail.goo.ne.jp.

DOI: $10.4187 /$ respcare.06109 result of reviewing errors and near-misses, which can lead to the discovery of important root causes and thus policy changes. Errors in the management of patients may occur for various reasons. Among such errors, there is little room for any error regarding mechanical ventilation because these may lead to more serious problems. ${ }^{3,4}$

Several previous studies have investigated serious patient safety incidents related to mechanical ventilators. ${ }^{5-8}$ Pham et $\mathrm{al}^{5}$ performed a cross-sectional analysis of ventilator-related adverse events from 3 incident reporting systems. They showed that ventilator-associated adverse events were frequently associated with human factor issues, airway/breathing circuit issues, and ventilator malfunctions. However, ventilator-related adverse events in the general care ward setting have not yet been explored. This is an important topic to study because considerable numbers of mechanically ventilated patients receive care in general medical care wards due to shortages of ICU beds or a prolonged need for mechanical ventilation. ${ }^{9-11}$

We therefore analyzed data on safety incident episodes, including near-misses, from a national collection of safety incidents involving mechanical ventilated pa- 
tients in ICU/high care units (HCUs) and in general care settings. The first aim of this study was to identify and compare the number of adverse clinical incidents and near-misses regarding mechanical ventilation in Japan between ICUs/high care units (HCUs) and general care wards. The second aim was to determine the risk factors of serious harm as a result of adverse events.

\section{Methods}

\section{Description of the Database}

To prevent adverse medical events and to promote patient safety, the Division of Adverse Event Prevention of Japan Council for Quality Health Care has conducted various activities and projects since 2004, including the collection of information on medical near-miss and adverse events, and the evaluation of the quality of medical services provided at hospitals. ${ }^{12}$ As of September 30, 2017, 1,464 hospitals and health care facilities in Japan $(\sim 17 \%$ of the total number of hospitals in Japan) were registered with this project. From January to December 2015, the project received 3,654 reports of medical adverse event information, 3,374 of which were reported by the medical institutions subject to the reporting requirements, with the remaining 280 being reported by voluntarily participating medical institutions. ${ }^{13}$

Medical adverse events subject to reporting fell into 3 categories: (1) apparent errors in the treatment or management resulting in death, mental or physical disabilities, unexpected treatment, treatment to an unexpected extent, or other medical procedure; (2) unapparent errors in treatment or management resulting in death, mental or physical disabilities, unexpected treatment, treatment to an unexpected extent, or other medical procedures (including events possibly associated with the treatment or management provided, limited to unexpected events); and (3) other than those described in (1) and (2), information conducive to the prevention of medical adverse events and their recurrence at medical institutions. ${ }^{12}$

Reported items on medical adverse events include month, year, and time period of occurrence; severity of event; overview of the event; the number of patients involved; the age, sex and indication for mechanical ventilation for each patient involved; the responsible party; and details of the event, including background, causal factors, and improvement measures. Moreover, the reports must, as a general rule, be made within 2 weeks of either the adverse event in question occurring or the medical institution becoming aware of the adverse event. Reports on adverse events are submitted via the Internet (SSL-encrypted communication) using the dedicated online reporting portal. Information is made available to interested parties and the general public via the project Website. Medical adverse

\section{QUICK LOOK}

\section{Current knowledge}

The ICU is the most appropriate place to care for mechanically ventilated patients, yet a considerable numbers of patients are cared for in the general care ward. Comparisons of the number of safety incidents reported as adverse clinical incidents and near-misses between ICUs/high care units (HCUs) and general care wards had not been explored.

\section{What this paper contributes to our knowledge}

From a national collection of safety incidents in the Japan Council for Quality Health Care database involving mechanically ventilated patients, most adverse events were identified as occurring in the general care setting rather than in the ICU/HCU setting. Humanfactor issues were most frequent in both settings, while knowledge-based errors occurred more frequently in the general care setting.

event information and medical near-miss event information can be perused on this Website, and users can download the selected events in any of 3 file formats: XML, $\mathrm{PDF}$, or CSV. At the time when this manuscript was prepared, the database search enabled users to search for details of 24,139 medical adverse events and 53,526 medical near-miss events. As part of the Project to Collect Medical Near-miss/Adverse Event Information, an Englishlanguage version of the annual report has been created each year since 2005. Reports and additional information are available at the project Website (www.med-safe.jp/contents/ english/index.html, Accessed May 9, 2018).

This study was approved by the Institutional Review Board at the Jichi Medical University Saitama Medical Center. We used anonymized data from the database with no link to individual patient information. Due to the anonymity of the data, the hospital review committees waived the need to review this study.

\section{Database Search Methods}

The events extracted from the database for use in this study included only ventilator-specific near-miss and adverse events reported between January 2010 and November 2017. Because this database is only available in Japanese, Japanese words meaning mechanical ventilator were used for data extraction. The database was searched for all events related to mechanical ventilator, and a free-text search was conducted to identify ventilator-specific events, such as equipment events, self- or unplanned extubation, 
and ventilator setting issues. We classified near-miss and adverse events reported from ICUs, HCUs, and emergency departments as occurring in the ICU/HCU setting, and all other events were classified as occurring in the general care setting. Near-miss and adverse events regarding operating theater equipment, ventilation in the operating room, neonatal ICU settings, and ventilator-associated pneumonia were excluded because the search criteria only focused on near-miss and adverse events occurring in ICU/HCU and general care settings. Near-miss and adverse events regarding noninvasive ventilation, which is frequently used in regular hospital wards, ${ }^{14}$ were also excluded in the present study.

We collected the following data from the database: patient sex, age, and location (ICU/HCU or general care wards); time and day of the week when the incident occurred; and the reporter's assessment regarding the possibility of residual disability. Based on the level of harm according to the reporter's assessment regarding the possibility of disabilities, the incidents were then classified into 5 groups: the patient experienced the event, but the event did not cause harm; low potential of residual disability; high potential of residual disability; event resulted in death; and unknown. Near-miss and adverse events were also identified and classified by reviewing the free-text description submitted at the time of the incident. Based on a previous study, ${ }^{5}$ we classified the near-miss and adverse events into 6 groups: ventilator malfunction, equipment damage, airway/breathing circuit issue, power source issue, human factor issues, and unknown or other.

James Reason, who proposed the image of Swiss cheese to explain the occurrence of system failures, classified human errors into 3 categories: knowledge-based (errors due to a lack of knowledge or experience with a particular process or situation); rule-based (misinterpretation or misuse of relevant data or applying the wrong rule); and skillbased (attention and memory failures, including omitted tasks). ${ }^{15-17}$ Based on this classification, we similarly classified human factor issues into 3 categories.

\section{Analysis of the Data}

We first performed analyses to compare the differences between the 2 settings (ICU/HCU and general care) for the following variables: time and day of the week when the incident occurred, the possibility of disabilities, presence of patient harm, and classification of ventilator events. Observed and expected numbers of events in the 2 groups were compared using the Pearson chi-square or Fisher exact tests (when the sample numbers are $<20$ events). Data were analyzed with JMP Pro12 (SAS Institute, Cary, North Carolina). All tests were 2-sided, and $P$ values $<.05$ were considered statistically significant.

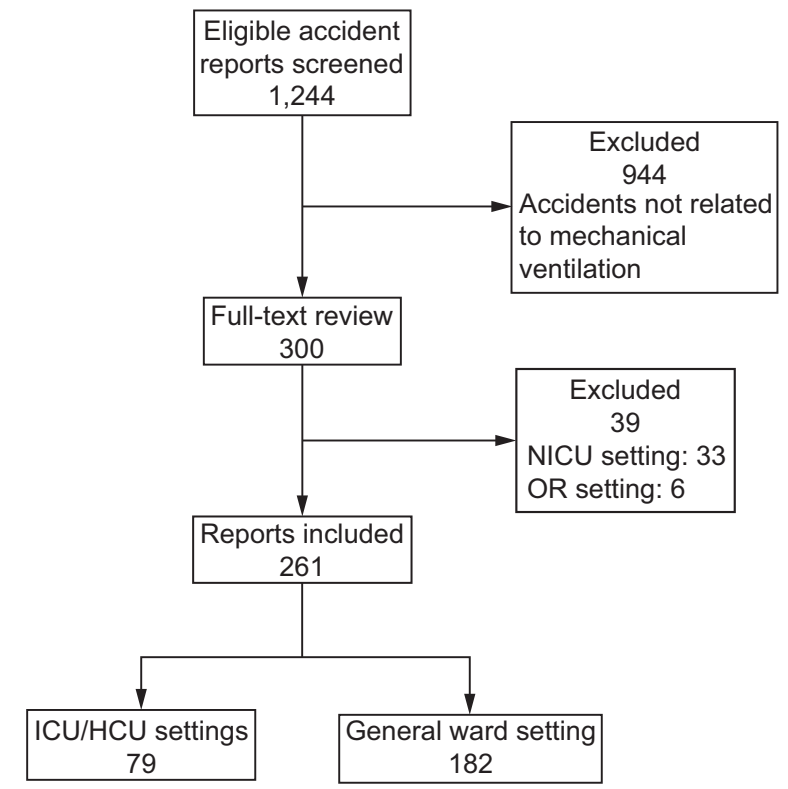

Fig. 1. Flow chart. $\mathrm{NICU}=$ neonatal $\mathrm{ICU} ; \mathrm{HCU}=$ high care unit.

\section{Results}

During the study period, we identified 1,244 adverse events that were potentially relevant to this study. Figure 1 shows the results of the article screening and selection process. We identified 300 accident reports by reviewing the free-text description, and data on 261 events were included in the final analysis in this study. Of the 261 events regarding mechanical ventilation, we identified 79 and 182 events from the ICU/HCU and general care settings, respectively. Table 1 shows the characteristics of the incidents and the comparison of the number of incidents by the day and time the incident occurred between the ICU/HCU and the general care settings. The number of patients who required mechanical ventilation secondary to neurological disease was greater in the general care setting than in the ICU/HCU setting, while the number of patients who required mechanical ventilation secondary to sepsis and trauma were greater in the ICU/HCU setting. In both the ICU/HCU and the general care settings, nurses were the most frequently involved responsible party in these incidents. Findings from our data analysis showed that there were no statistically significant differences regarding time and day of the week between incidents occurring in either care setting. However, accident rates tended to increase on the weekends compared to the weekdays.

A comparison of the causes of ventilator-related adverse events between the ICU/HCU and general care settings is shown in Table 2. In 261 events, 10 (4\%), 13 (5\%), 97 (37\%), $1(<1 \%), 0$, and $141(54 \%)$ events occurred due to ventilator malfunction, equipment damage, airway/breathing circuit issues, power source issues, gas supply issues, and 
Table 1. Characteristics and Comparisons of Day and Time of Incidents

\begin{tabular}{|c|c|c|c|c|}
\hline & Total & $\mathrm{ICU} / \mathrm{HCU}$ & General Care Ward & $P$ \\
\hline \multicolumn{5}{|l|}{ Patient age, y } \\
\hline $0-9$ & $31(12)$ & $7(9)$ & $24(13)$ & $.40 *$ \\
\hline $10-19$ & $6(2)$ & $3(4)$ & $3(2)$ & $.37 *$ \\
\hline $20-69$ & $110(42)$ & $39(49)$ & $71(39)$ & $.13 \dagger$ \\
\hline $70-79$ & $61(23)$ & $14(18)$ & $47(26)$ & $.16^{*}$ \\
\hline$\geq 80$ & $53(20)$ & $16(20)$ & $37(20)$ & $.99 *$ \\
\hline \multicolumn{5}{|l|}{ Indication of mechanical ventilation } \\
\hline Cardiovascular & $31(12)$ & $12(15)$ & $19(10)$ & $.27 *$ \\
\hline Stroke & $6(2)$ & $4(5)$ & $2(1)$ & $.07 *$ \\
\hline Neurological & $67(26)$ & $7(9)$ & $60(33)$ & $.002^{*}$ \\
\hline Postsurgical & $37(14)$ & $10(13)$ & $27(15)$ & $.70^{*}$ \\
\hline Respiratory & $75(29)$ & $24(30)$ & $51(28)$ & $.70 \dagger$ \\
\hline Post cardiac arrest & $7(3)$ & $3(4)$ & $4(2)$ & $.43 *$ \\
\hline Trauma & $11(4)$ & $7(9)$ & $4(2)$ & $.02 *$ \\
\hline Sepsis & $17(7)$ & $11(14)$ & $6(3)$ & $.004 *$ \\
\hline Others or Unknown & $10(4)$ & $1(1)$ & $9(5)$ & $.29 *$ \\
\hline \multicolumn{5}{|l|}{ Responsible party } \\
\hline Nurse & $212(81)$ & $60(76)$ & $152(84)$ & $.15 \dagger$ \\
\hline Physician & $43(17)$ & $17(21)$ & $26(14)$ & $.15^{*}$ \\
\hline Physical therapist & $3(1)$ & $1(1)$ & $2(1)$ & $.99 *$ \\
\hline Biomedical equipment technician & $3(1)$ & $1(1)$ & $2(1)$ & $.99 *$ \\
\hline \multicolumn{5}{|l|}{ Day the incident occurred } \\
\hline Weekday & $81(31)$ & $26(33)$ & $55(30)$ & $.67 \dagger$ \\
\hline Weekend & $180(69)$ & $53(67)$ & $127(70)$ & \\
\hline \multicolumn{5}{|l|}{ Time the incident occurred } \\
\hline Daytime (8 AM-8 PM) & $160(61)$ & $50(63)$ & $110(60)$ & $.66 \dagger$ \\
\hline Nighttime (8 PM-8 AM) & $101(39)$ & $29(37)$ & $72(40)$ & \\
\hline $\begin{array}{l}\text { Data shown as no. }(\%) \text {. There were } 261 \text { total ev } \\
* P \text { value from the Fisher exact test. } \\
\dagger P \text { value from the chi-square test. } \\
\mathrm{HCU}=\text { high care unit }\end{array}$ & ents, and 182 & rents. & & \\
\hline
\end{tabular}

Table 2. Comparison of Causes of Ventilator-Related Adverse Events

\begin{tabular}{lcccc}
\hline \hline & Total & ICU/HCU & $\begin{array}{c}\text { General } \\
\text { Care } \\
\text { Ward }\end{array}$ & $P$ \\
\hline $\begin{array}{l}\text { Ventilator malfunction } \\
\text { Equipment damage }\end{array}$ & $10(4)$ & $4(5)$ & $6(3)$ & $.49^{*}$ \\
$\begin{array}{l}\text { Airway/breathing } \\
\quad \text { circuit issue }\end{array}$ & $97(3)$ & $6(8)$ & $7(4)$ & $.22^{*}$ \\
Power source issue & $1(<1)$ & $25(32)$ & $72(40)$ & $.22 \dagger$ \\
Gas supply issue & 0 & 0 & $1(<1)$ & $.99^{*}$ \\
Human factor issue & $141(54)$ & $44(55)$ & $96(53)$ & $.66 \dagger$ \\
Others & 0 & 0 & 0 & \\
& & & & \\
\end{tabular}

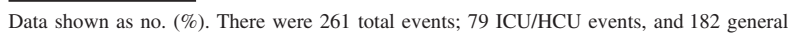
care ward events.

* $P$ value from the Fisher exact test.

$\dagger P$ value from the chi-square test.

$\mathrm{HCU}=$ high care unit human factor issues, respectively. However, the comparison of each cause between the ICU/HCU and the general care settings showed no significant difference. Table 3 shows the comparison of incident numbers of the degree of harm due to adverse events between the ICU/HCU and general care settings. In 261 accidents that could be classified by the level of harm, 161 (62\%), 47 (18\%), 29 (11\%), and $20(8 \%)$ were classified as causing no obvious harm, resulting in low or high potential of residual disability, or resulting in death, respectively. Lack of harm was significantly higher in the ICU/HCU than in general care $(P=$ $.002)$. Although there were no significant differences between the ICU/HCU and general care settings, the rate of accidents that could cause serious harm (ie, high potential for residual disability and death) were greater in the general care setting.

We identified 702 near-miss events regarding mechanical ventilation in the ICU/HCU and general care settings. Table 4 summarizes the number of near-miss events according to ventilator-event classifications and the compar- 
Table 3. Comparison of Degree of Harm Due to Adverse Events

\begin{tabular}{|c|c|c|c|c|}
\hline & Total & $\mathrm{ICU} / \mathrm{HCU}$ & $\begin{array}{l}\text { General } \\
\text { Care } \\
\text { Ward }\end{array}$ & $P$ \\
\hline $\begin{array}{l}\text { Events that did not cause } \\
\text { patient harm }\end{array}$ & $161(62)$ & $60(76)$ & $101(56)$ & $.002 \dagger$ \\
\hline $\begin{array}{l}\text { Low potential of residual } \\
\text { disability }\end{array}$ & $47(18)$ & $8(10)$ & $39(21)$ & $.035^{*}$ \\
\hline $\begin{array}{l}\text { High potential of residual } \\
\text { disability }\end{array}$ & $29(11)$ & $7(9)$ & $22(12)$ & $.53^{*}$ \\
\hline Event resulted in death & $20(8)$ & $3(4)$ & $17(9)$ & $.13 *$ \\
\hline Unknown & $4(1)$ & $1(1)$ & $3(2)$ & $.99 *$ \\
\hline \multicolumn{5}{|c|}{$\begin{array}{l}\text { Data shown as no. }(\%) \text {. There were } 261 \text { total events; } 79 \mathrm{ICU} / \mathrm{HCU} \text { events, and } 182 \text { general } \\
\text { care ward events. } \\
* P \text { value from the Fisher exact test. } \\
\dagger P \text { value from the chi-square test. } \\
\mathrm{HCU}=\text { high care unit }\end{array}$} \\
\hline
\end{tabular}

Table 4. Comparison of Causes of Ventilator-Related Near-Miss Events

\begin{tabular}{|c|c|c|c|c|}
\hline & Total & $\mathrm{ICU} / \mathrm{HCU}$ & $\begin{array}{c}\text { General } \\
\text { Care } \\
\text { Ward }\end{array}$ & $P$ \\
\hline Ventilator malfunction & $51(7)$ & $22(9)$ & 29 (6) & $.19 \dagger$ \\
\hline Equipment damage & $45(6)$ & $11(5)$ & $34(7)$ & $.15^{*}$ \\
\hline $\begin{array}{l}\text { Airway/breathing } \\
\text { circuit issue }\end{array}$ & $56(8)$ & $16(6)$ & $40(9)$ & $.38 *$ \\
\hline Power source issue & $17(2)$ & $4(2)$ & $13(3)$ & $.44 *$ \\
\hline Gas supply issue & $7(1)$ & $2(1)$ & $5(1)$ & $.99 *$ \\
\hline Human factor issue & $522(74)$ & $188(77)$ & $334(73)$ & $.23 \dagger$ \\
\hline Others & $4(1)$ & $1(<1)$ & $3(1)$ & $.99 *$ \\
\hline \multicolumn{5}{|c|}{$\begin{array}{l}\text { Data shown as no. }(\%) \text {. There were } 702 \text { total events; } 244 \mathrm{ICU} / \mathrm{HCU} \text { events, and } 458 \text { general } \\
\text { care ward events. } \\
* P \text { value from the Fisher exact test. } \\
\dagger P \text { value from the chi-square test. } \\
\mathrm{HCU}=\text { high care unit }\end{array}$} \\
\hline
\end{tabular}

isons between the ICU/HCU and general care settings. Among the near-miss events, human factor issues were the most frequent in both settings, although there were no significant differences regarding all issues between the 2 settings. Table 5 shows the comparison of the different categories of human factor issues related to mechanical ventilation between the ICU/HCU and the general care settings. In the near-miss events, the knowledge-based error rate was significantly higher in the general care setting $(P=.02)$. However, in the ICU/HCU setting, skill-based error rates were significantly higher $(P=.004$ and .02 , respectively).

\section{Discussion}

In this study, we identified 261 adverse events and 702 near-miss events relating to mechanical ventilation from the Japan Council for Quality Health Care open database. Our analysis revealed at least 20 adverse events resulted in death in Japan between 2010 and 2017. Moreover, among all adverse events, 19\% (49 of 261 events) caused serious harm (ie, residual disability or death). Of all adverse events, 54\% were due to human factor issues, while $76 \%$ of near-miss events were due to human factor issues. Human factor issues were reported most frequently in both the ICU/HCU and the general care settings, while knowledge-based error rates were significantly higher in the general care settings.

Our study has several notable strengths. This is the first study to analyze data on adverse events regarding mechanical ventilation, with a focus on the comparison between the ICU/HCU setting and the general care setting. In addition, this is the first report to analyze data on incident reports from a national collection of patient safety incidents involving mechanical ventilated individuals in Japan. Finally, we classified human errors into 3 categories to describe the causes of incidents in detail. We believe that our results are very important additions to the accumulated body of evidence related to these areas.

Accidents involving medical devices have occurred and will continue to occur for many reasons, including device design, lack of knowledge, and human error. Due to the small number of mechanical ventilator-related factors, we did not examine this aspect in detail; however, our findings showed that the most commonly reported ventilatorrelated adverse events were human factor issues and airway/breathing circuit issues, which is consistent with a previous study on ventilator-related adverse events. ${ }^{5}$ Moreover, we revealed that the knowledge-based error rates were significantly higher in general care settings. Respiratory therapists are specialized health care practitioners trained in pulmonary medicine; however, aside from the United States and Canada, very few countries have a dedicated professional role for respiratory health. Because there are no respiratory therapists in Japan, nurses were responsible for a greater proportion of care of mechanically ventilated patients, ${ }^{18}$ and the same may apply for practice in other countries. $\mathrm{Li}$ et $\mathrm{al}^{19}$ reported that variable clinical practices in ICU respiratory care exist and are provided mostly by nurses and physicians because of the lack of respiratory therapists. Experience-based knowledge was indicated by nurses as one of the categories of their sources of knowledge in practice. ${ }^{20}$ However, nurses working in general care wards experience challenges when dealing with patients who are mechanically ventilated due to a lack of experience and skill. This lack of knowledge and experience might have led to the reported rates of accidents with serious harm, which tend to be higher in the general care setting. Indeed, caring for patients on mechanical ventilation in the general ward causes dissatisfaction among staff, thereby putting patients at more risk. ${ }^{21}$ 
Mechanical Ventilation-Related Safety Incidents

Table 5. Comparison of Human Factor Issues Related to Mechanical Ventilation

\begin{tabular}{|c|c|c|c|c|c|c|c|c|}
\hline & \multicolumn{4}{|c|}{ Near-Miss Events } & \multicolumn{4}{|c|}{ Adverse Events } \\
\hline & Total & $\mathrm{ICU} / \mathrm{HCU}$ & General Care Ward & $P$ & Total & ICU/HCU & General Care Ward & $P$ \\
\hline Human factor issue, no. & 522 & 188 & 334 & & 141 & 44 & 97 & $.66 \dagger$ \\
\hline Knowledge-based, no. (\%) & $69(13)$ & $16(9)$ & $543(16)$ & $.02 *$ & $10(7)$ & 0 & $10(10)$ & $.063^{*}$ \\
\hline Rule-based, no. (\%) & $46(9)$ & $12(6)$ & $34(10)$ & $.15^{*}$ & $3(2)$ & 0 & $3(3)$ & $.55^{*}$ \\
\hline Skill-based, no. (\%) & 407 (78) & $160(85)$ & 247 (74) & $.004 \dagger$ & $128(91)$ & $44(100)$ & $84(88)$ & $.02 \dagger$ \\
\hline $\begin{array}{l}{ }^{*} P \text { value from the Fisher exact test. } \\
\dagger P \text { value from the chi-square test. } \\
\mathrm{HCU}=\text { high care unit }\end{array}$ & & & & & & & & \\
\hline
\end{tabular}

Although there were no significant differences between the ICU/HCU and general care settings, the rate of incidents that could cause serious harm were greater in general care, which should not be ignored.

Because ventilators play a crucial safety role, patients should be treated in a safe environment, protected from avoidable harm. Therefore, the Society of Critical Care Medicine's guidelines for ICU admissions recommend mechanical ventilation as the highest priority indication for admission to ICUs. ${ }^{22}$ It has been reported that the general care ward offers poorer monitoring, is associated with more endotracheal tube-related complications, and provides less active ventilator management. ${ }^{23}$ In Japan, a tracheostomy tube is usually placed for patients requiring mechanical ventilation in the wards; however, there are no explicit rules for the use of ward beds for these patients. Moreover, ICU bed resources in Japan are limited in number when compared to the United States. ${ }^{18}$ Therefore, if prolonged mechanical ventilation patients are stable enough to be transferred to a general care ward, they often continue to receive care in those wards. Although it is unusual that invasive mechanical ventilation is delivered in a general care ward in the United States, our report might provide a reference value for the incidence of adverse events for patients receiving ventilator support in general care wards, and it may also attract attention to similar information for patients on home ventilation. ${ }^{24,25}$

Our study had several limitations. First, this was a retrospective analysis of an existing database. Despite using a uniform method of data collection, the quality of the data in this database varied because the data were submitted by the staff of individual facilities. Although there was no validation of this database, an English-language version of the Annual Report has been created each year since 2005, and the Quarterly and Annual Reports contain large volumes of information. When this manuscript was prepared, the database search function enabled users to access details of 24,139 medical adverse events and 53,526 medical near-miss events. Preliminary analyses provide insight into the potential value of the early detection of risks to patient safety before serious harm can occur. Second, $>1,000$ hospitals and health care facilities in Japan have joined this national health database; however, the reporting of adverse events is dependent on each health care professional, and adverse events may thus be underreported. Because error-reporting systems may only capture a fraction of the actual errors, the true error frequency may be many times greater than what is actually reported. The types of errors that are reported will differ not just on the actual number and type of true errors occurring, but also on the ability to recognize and report them in the first place. Therefore, our results may underestimate the actual occurrence of safety incidents. However, we extracted all data from the database and conducted a free-text search to obtain even more precise information. Third, as we described previously, two authors (TK, KM) categorized all reports. Although the professor of the department of biomedical engineering (KM) supervised this analysis, subjective bias of categorization might exist.

\section{Conclusion}

We identified at least 20 adverse events that resulted in death in Japan between 2010 and 2017 from the Japan Council for Quality Health Care open database. Moreover, we found that human factor issues were the most frequent issues in both ICU/HCU and general care settings, and knowledge-based error rates were significantly higher in the general care ward. Our findings suggest that proper education and training is needed to minimize patient safety incidents in facilities without respiratory therapists.

\section{REFERENCES}

1. Barach P, Small SD. How the NHS can improve safety and learning. By learning free lessons from near misses. BMJ 2000;320(7251): 1683-1684.

2. Vincent CA. Analysis of clinical incidents: a window on the system not a search for root causes. Qual Saf Health Care 2004;13(4):242243.

3. Kaur M, Pawar M, Kohli JK, Mishra S. Critical events in intensive care unit. Indian J Crit Care Med 2008;12(1):28-31.

4. Drews FA, Musters A, Samore MH. Advances in patient safety error producing conditions in the intensive care unit. In: Henriksen K, 


\section{Mechanical Ventilation-Related Safety Incidents}

Battles JB, Keyes MA, Grady ML. Advances in Patient Safety: New Directions and Alternative Approaches (Vol 3: Performance and Tools). Rockville, MD: Agency for Healthcare Research and Quality (US); 2008.

5. Pham JC, Williams TL, Sparnon EM, Cillie TK, Scharen HF, Marella WM. Ventilator-related adverse events: a taxonomy and findings from 3 incident reporting systems. Respir Care 2016;61(5):621-631.

6. Tanios MA, Epstein SK, Livelo J, Teres D. Can we identify patients at high risk for unplanned extubation? A large-scale multidisciplinary survey. Respir Care 2010;55(5):561-568.

7. Snijders C, van Lingen RA, van der Schaaf TW, Fetter WP, Molendijk HA. Incidents associated with mechanical ventilation and intravascular catheters in neonatal intensive care: exploration of the causes, severity and methods for prevention. Arch Dis Child Fetal Neonatal Ed. 2011;96(2):F121-F126.

8. Thomas AN, Galvin I. Patient safety incidents associated with equipment in critical care: a review of reports to the UK National Patient Safety Agency. Anaesthesia 2008;63(11):1193-1197.

9. Canadian Health Services Research Foundation. Providing more choices for those who depend on ventilators. Healthc Policy 2009; 5(1):32-34

10. Scheinhorn DJ, Hassenpflug MS, Votto JJ, Chao DC, Epstein SK, Doig GS, et al. Ventilator-dependent survivors of catastrophic illness transferred to 23 long-term care hospitals for weaning from prolonged mechanical ventilation. Chest 2007;131(1):76-84.

11. Wongsurakiat P, Sangsa N, Tangaroonsanti A. Mechanical ventilation of patients hospitalized on general medical ward: outcomes and prognostic factors. J Med Assoc Thai 2016;99(7):772-776.

12. The Japan Council for Quality Health Care Division of Adverse Event Prevention. http://wwwmed-safejp/contents/english/indexhtml, Accessed 15 Nov 2017.

13. The Japan Council for Quality Health Care Division of Adverse Event Prevention Project to Collect Medical Near-Miss/Adverse Event Information 2015 Annual Report. http://wwwmed-safejp/pdf/ year_report_english_2015pdf.
14. Farha S, Ghamra ZW, Hoisington ER, Butler RS, Stoller JK. Use of noninvasive positive-pressure ventilation on the regular hospital ward: experience and correlates of success. Respir Care 2006;51(11):12371243.

15. Reason J. Human error: models and management. BMJ 2000; 320(7237):768-770.

16. Perneger TV. The Swiss cheese model of safety incidents: are there holes in the metaphor? BMC Health Serv Res 2005;5(1):71.

17. Reason J. Understanding adverse events: human factors. Qual Saf Health Care 1995;4(2):80-89.

18. Sirio CA, Tajimi K, Taenaka N, Ujike Y, Okamoto K, Katsuya H. A cross-cultural comparison of critical care delivery: Japan and the United States. Chest 2002;121(2):539-548

19. Li J, Zhan QY, Liang ZA, Tu ML, Sun B, Yao XL, et al. Respiratory care practices and requirements for respiratory therapists in Beijing intensive care units. Respir Care 2012;57(3):370-376.

20. Estabrooks CA, Rutakumwa W, O'Leary KA, Profetto-McGrath J, Milner M, Levers MJ, et al. Sources of practice knowledge among nurses. Qual Health Res 2005;15(4):460-476.

21. Faidy A, Ouseph B, Yutuc N, Melki S, Tamonan E, Jamaly A, et al. Care of mechanical ventilated patients in general ward: nurses perspective. GSTF J Nurs Health Care. 2014;1(2):1-5.

22. Nates JL, Nunnally M, Kleinpell R, Blosser S, Goldner J, Birriel B, et al. ICU admission, discharge, and triage guidelines: a framework to enhance clinical operations, development of institutional policies, and further research. Crit Care Med 2016;44(8):1553-1602.

23. Hersch M, Sonnenblick M, Karlic A, Einav S, Sprung CL, Izbicki G. Mechanical ventilation of patients hospitalized in medical wards vs the intensive care unit: an observational, comparative study. J Crit Care 2007;22(1):13-17.

24. Kun SS, Edwards JD, Ward SL, Keens TG. Hospital readmissions for newly discharged pediatric home mechanical ventilation patients. Pediatr Pulmonol 2012;47(4):409-414.

25. Simonds AK. Risk management of the home ventilator dependent patient. Thorax 2006;61(5):369-371 